\title{
Nanotribological Properties of Nanotextured Ni-Co Coating Surface Measured with AFM Colloidal Probe Technique
}

\author{
Jiaxiang Man$^{1}$, Haifeng Yang*1, Yanqing Wang², Cheng Yan*3, Shanqing Zhang*4 \\ ${ }^{1}$ College of Mechanical \& Electrical Engineering, China University of Mining \& Technology, No1, \\ Daxue Road, Xuzhou, Jiangsu, 221116, China \\ E-mail: hfyang@cumt.edu.cn \\ ${ }^{2}$ College of Materials Science \& Engineering, China University of Mining \& Technology, No1, \\ Daxue Road, Xuzhou, Jiangsu, 221116, China \\ ${ }^{3}$ School of Chemistry, Physics and Mechanical Engineering, Queensland University of Technology, \\ Brisbane, QLD 4001, Australia \\ ${ }^{4}$ Centre for Clean Environment and Energy, Environmental Futures Research Institute, Griffith \\ School of Environment, Griffith University, Gold Coast QLD 4222, Australia
}

Surface-texturing is a useful method of modifying surface frictional performance. A simple, novel, easily-controlled method was used to fabricate different kinds of textures on an Ni-Co coating surface. The nanotribological properties were characterised by atomic force microscope (AFM) with a colloidal probe. The results showed that, compared to the original Ni-Co coating surface, the nanotextured surface can adjust the surface friction forces. The half-elliptic patterns have better tribological properties than hemispherical patterns. Therefore, both laser energy and laser scanning speed will influence the friction performances of Ni-Co coating surfaces.

DOI: 10.2961/jlmn.2017.01.0004

Keywords: laser direct writing, Ni-Co, nanotextured surface, AFM, nanotribological properties.

\section{Introduction}

Research into the use of surface-texturing to change the contact area between surfaces has reached the consensus that it adjusts the surface frictional performance. At a macro-scale, the regular distributed holes on the piston ring are one of the earliest and most familiar commercial applications of surface-texturing. Nowadays with the rapid development of nanotechnology, many interesting phenomena have been found at the nanometric scale [1]. The mechanical system is gradually stepping into the nanoscale. More and more miniaturised, and integrated components and devices such as electrostatic micro-motors, micro-actuators, micro-sensors, and micro-systems, have attracted many researchers [2-3]. However, as the mechanical system or components shrink to the micro/nanometre scale, adhesion and friction problems, because of the dramatically increased surface-area-to-volume ratio [4], become a major reason for the failure of MEMS [5] and limit further developments in the MEMS fields. J. Bons et.al [6-8] has investigated the tribological performance of micro/nanostructure surface induced by femtosecond laser. In their tribology measurements, larger loads of $1 \mathrm{~N}$ and ball diameter of $10 \mathrm{~mm}$ can easily destroy the micro/ nanostructures of metal surface. However, AFM colloidal probe technique can effectively reveal the friction mechanism of micro/nanostructure surface, which have been more and more applications in tribology research. According to the frictional behaviour after surface texturing, many scholars [9-12] have adopted various methods, for instance laser lithography, electro-beam lithography and chemical vapour deposition, to fabricate nanotextured surfaces and investigate its nanotribological properties. Zhao [13] investigated the nanotribological behaviour of Au surfaces with different micro/nano-textures and the corresponding chemical modification thereof. The results showed that surface textures with micro/nano-scale cylindrical holes and chemical modified by ODT self-assembled monolayers can improve the nanotribological performance of an $\mathrm{Au}$ surface. Rahul Premachandran Nair and Min Zhou [14] used a method of aluminium-induced crystallisation (AI-C) of amorphous silicon (a-Si) to fabricate a controlled nanotextured surface and tested its friction characteristics. The result showed that by changing the a-Si thickness and annealing conditions, various nanotextured surfaces were produced. NTSs had significantly altered surface frictional properties. Both texture height and density were found to affect the adhesion and friction performances of the nanotextured surfaces.

The AFM is a useful tool with which to measure the friction force between contact surfaces [14]. The use of different kinds of probes can simulate different kinds of frictional pairs. Generally the contact model probe with tip radii in the range of several tens of nanometres is widely used to investigate surface tribological properties because of its high sensitivity and low-cost; however the sharp tip an easily penetrate into soft surfaces or easily wear in the measurement of rigid surfaces. This influences measurement accuracy when such a contact model probe was used to measure friction forces [15]. To overcome this problem, spherical colloidal particles with radii in the range of several to several tens of microns were attached to the AFM cantilevers can be used as probes to measure the surface friction [16]. Compared to the contact model probe, the colloidal probe has advantages in many respects, including a larger contact area which distributes the 
pressure over the sample surface [17] and the higher signal-to-noise ratio between the surface and colloidal probe during force measurement [18]. Due to these advantages, the colloidal probe has been used to measure friction forces by many scholars. Zhang [19] used a colloidal probe to acquire friction force images of micro/nano-patterned surfaces. A difference in friction force produced a contrast on the friction force images when the colloidal probe slid over different regions of the patterned polymer surfaces. Hartmut R. Fischer and Edwin R.M. Gelinck [20] used an AFM with colloidal probes varying from $1 \mathrm{~nm}$ to $8 \mu \mathrm{m}$ contact diameter to measure the adhesion on an Si surface. The results show that a larger contacting surface enhances the quality of the measured adhesion values.

In this work, due to the initially good friction-reducing performance of the Ni-Co alloy coating itself, stainless steel with an electrodeposited Ni-Co alloy coating was selected for testing. Laser direct writing was used to fabricate nanotextures on the Ni-Co coating surface. The surface morphology of the nanotextures on the Ni-Co coating surface were characterised by SEM. The nanotribological properties of the nanotexturing on the $\mathrm{Ni}$-Co coating surface were investigated by AFM with a colloidal probe.

\section{Experimental work}

The samples used in the experiments were all derived from a 316L stainless steel. The surface of the stainless steel was coated by electrodeposition of a layer of $\mathrm{Ni}-\mathrm{Co}$ alloy. The electrodeposition processing parameters and composition of the solution in the bath are shown in Table 1.

A laser direct writing system was used to fabricate the different kinds and sizes of nanotextures. The schematic diagram of the laser direct writing system is shown in Fig. 1. An ultraviolet laser (DSH-355-10, PHOTONICS INDUSTRIES, USA) with a working wavelength of 355 $\mathrm{nm}$, pulse width of $12 \mathrm{~ns}$ and repetition rate of $7 \mathrm{KHz}$ was selected as the laser generator used to manufacture nanostructures on the Ni-Co coating surface. The laser beam was reflected by two angled, $45^{\circ}$ mirrors (M1, M2) and then the reflected laser beam was incident to a laser marker which is controlled by a computer and can control the motion of the laser beam. The samples were set perpendicularly to the laser marker. The laser processing parameters are listed in Table 2.

Table 1 The composition of the electroplating bath solution and processing parameters

\begin{tabular}{|c|c|c|c|}
\hline \multicolumn{2}{|c|}{ Solution composition } & \multicolumn{2}{|c|}{$\begin{array}{l}\text { Electrodeposition } \\
\text { processing parameters }\end{array}$} \\
\hline Composition & Content/ g L-1 & \multirow{2}{*}{$\begin{array}{c}\text { Temperature( } \\
\left.{ }^{\circ} \mathrm{C}\right)\end{array}$} & \multirow{2}{*}{50} \\
\hline Cobalt sulphate & 20 & & \\
\hline Nickel sulphate & 60 & \multirow{3}{*}{$\mathrm{pH}$} & \multirow{3}{*}{3.5 to 4.5} \\
\hline Nickel chloride & 30 & & \\
\hline Boric acid & 30 & & \\
\hline
\end{tabular}

Table 2 Laser processing parameters

\begin{tabular}{|c|c|c|c|}
\hline \multicolumn{3}{|c|}{ Laser processing parameter } \\
\hline $\begin{array}{c}\text { Laser energy } \\
\text { density }\left(\mathrm{J} / \mathrm{cm}^{2}\right)\end{array}$ & $\begin{array}{c}\text { Scanning speed } \\
(\mathrm{mm} / \mathrm{s})\end{array}$ & $\begin{array}{c}\text { Scan } \\
\text { interval }\end{array}$ & $\begin{array}{c}\text { Laser spot } \\
\text { radius }\end{array}$ \\
\hline $\begin{array}{c}0.01,0.03,0.05, \\
0.18\end{array}$ & $\begin{array}{c}2.54,7.62,15.24, \\
25.4\end{array}$ & $\begin{array}{c}0.01 \\
\mathrm{~mm}\end{array}$ & $15 \mu \mathrm{m}$ \\
\hline
\end{tabular}
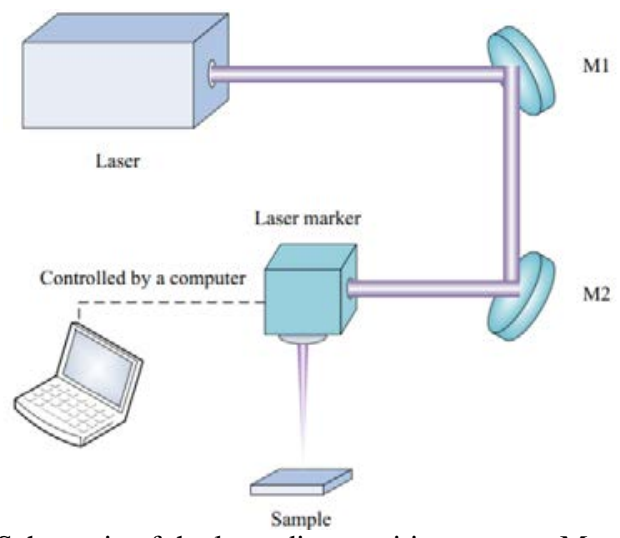

Fig.1 Schematic of the laser direct writing system, M: mirror.

The surface morphology and nanostructure of the coating surface was characterised by scanning electron microscopy (SEM). The friction force performance was tested by commercial AFM (CSPM5500, Benyuan Nano-Instrument, China). A commercial colloidal probe with a $10 \mu \mathrm{m}$ radius, $\mathrm{SiO}_{2}$ colloidal spherical tip (Novascan. Inc.) (Fig. 2) was used. The AFM contact mode was used with a scanning rate of $1 \mathrm{~Hz}$ and scanning length of 50.0 $\mu \mathrm{m}$ to measure friction force. The loads were changed from $0 \mathrm{~V}$ to $1 \mathrm{~V}$.

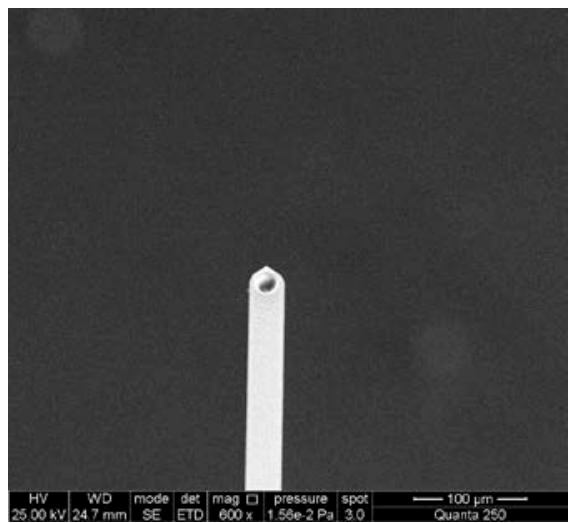

Fig.2 SEM topography of $\mathrm{SiO}_{2}$ colloidal probe

\section{Results and discussion}

\subsection{Laser direct writing of nanotextures}

There are several major parameters controlling the laser direct writing process, such as laser energy density and scanning velocity. Fig. 3 shows a number of SEM images at laser energy densities of $0.03 \mathrm{~J} / \mathrm{cm}^{2}, 0.05 \mathrm{~J} / \mathrm{cm}^{2}$, and $0.18 \mathrm{~J} / \mathrm{cm}^{2}$ at the same scanning speed of $15.24 \mathrm{~mm} / \mathrm{s}$. Fig. 3(a) shows an original surface morphology of the Ni-Co alloy coating without laser direct writing. It can be seen that there are lots of irregular sizes and random distributed 
bumps and grooves on the unprocessed coating surface. Furthermore, the heights of the surface particles are different. After processing by laser scan writing at 0.03 $\mathrm{J} / \mathrm{cm}^{2}$ (Fig. 3(b)), some regular protrusions can be found on the surface and the height of the surface protrusions was the same. The previous surface defects were replaced by uniform, regular patterns. As the laser energy density continuously increased to $0.05 \mathrm{~J} / \mathrm{cm}^{2}$ and $0.18 \mathrm{~J} / \mathrm{cm}^{2}$, in Figs 3(c) and 3(d), the hemispherical nanoprotrusions were replaced by half-elliptic nanoprotrusions. The processed region has a tendency to become flat. When the laser energy density exceeded $0.25 \mathrm{~J} / \mathrm{cm}^{2}$, the patterns on the laser processing region disappeared and the processed area was at its smoothest and flattest. Hence different kinds of surface textures can be fabricated at different laser energy densities. The regular hemispherical nanoprotrusions and half-elliptical nanoprotrusions can be acquired by adjusting the energy density.

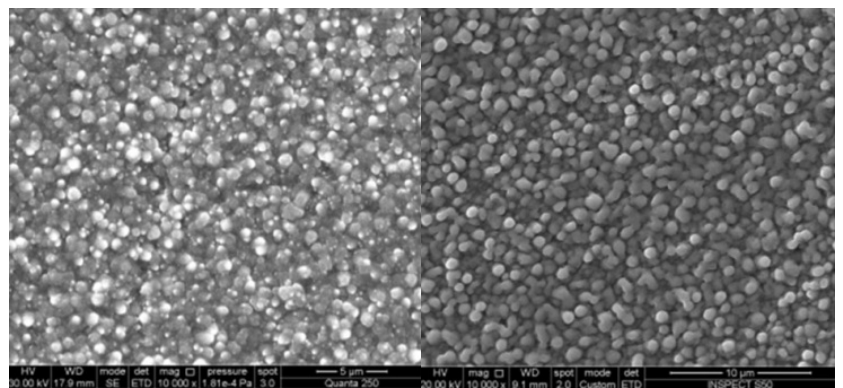

(a)

(b)

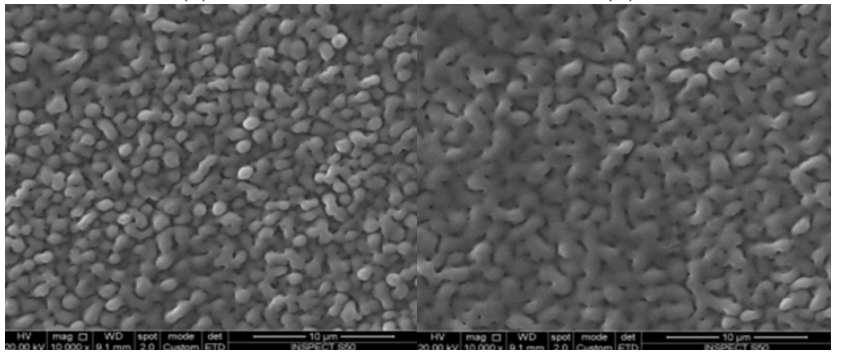

(c)

(d)

Fig.3 SEM images of (a) Ni-Co alloy coating surface before laser-beam treatment and the processing region under laser treatment at (b) $0.03 \mathrm{~J} / \mathrm{cm} 2$; (c) $0.05 \mathrm{~J} / \mathrm{cm} 2$; (d) $0.18 \mathrm{~J} / \mathrm{cm} 2$.

Fig. 4 shows the surface morphology of laser processed regions produced at different scanning velocities (2.54 $\mathrm{mm} / \mathrm{s}, 7.62 \mathrm{~mm} / \mathrm{s}, 15.24 \mathrm{~mm} / \mathrm{s}$, and $25.4 \mathrm{~mm} / \mathrm{s}$ ) at two energy densities $\left(0.03 \mathrm{~J} / \mathrm{cm}^{2}\right.$ and $\left.0.05 \mathrm{~J} / \mathrm{cm}^{2}\right)$. As mentioned, the laser energy density can control the type of nanotexture. The typical hemispherical nanoprotrusions and half-elliptical nanoprotrusions have been selected to investigate the relationship between scanning velocities and surface topography. In Figs 4(a) to 4(d), hemispherical nanoprotrusions on the Ni-Co coating surface are obtained by four different scanning velocities $-2.54 \mathrm{~mm} / \mathrm{s}, 7.62$ $\mathrm{mm} / \mathrm{s}, 15.24 \mathrm{~mm} / \mathrm{s}$, and $25.4 \mathrm{~mm} / \mathrm{s}$ at $0.03 \mathrm{~J} / \mathrm{cm}^{2}$. Figs $4(\mathrm{e})$ to 4(h) show half-elliptic nanoprotrusions on the $\mathrm{Ni}-\mathrm{Co}$ coating surface made at scanning velocities of $2.54 \mathrm{~mm} / \mathrm{s}$, $7.62 \mathrm{~mm} / \mathrm{s}, 15.24 \mathrm{~mm} / \mathrm{s}$, and $25.4 \mathrm{~mm} / \mathrm{s}$ at $0.05 \mathrm{~J} / \mathrm{cm}^{2}$. From these images of hemispherical nanoprotrusions, it can be concluded that the sizes thereof were inversely proportional to the scanning velocities. As scanning velocities increased, the nanoprotrusions on the coating surface became smaller. From SEM images of half-elliptic nanoprotrusions, it was found that the half-elliptic nanoprotrusions grew bigger when the scanning velocities decreased. Hence scanning velocity can control the size of nanoprotrusion produced.

In summary, different kinds of nanotextured surface may be fabricated through changing the laser energy density and the size of hemispherical and half-elliptic nanoprotrusions can be changed by using different scanning velocities. Therefore, laser direct writing is an effective method of fabricating controllable nanotextured surfaces.

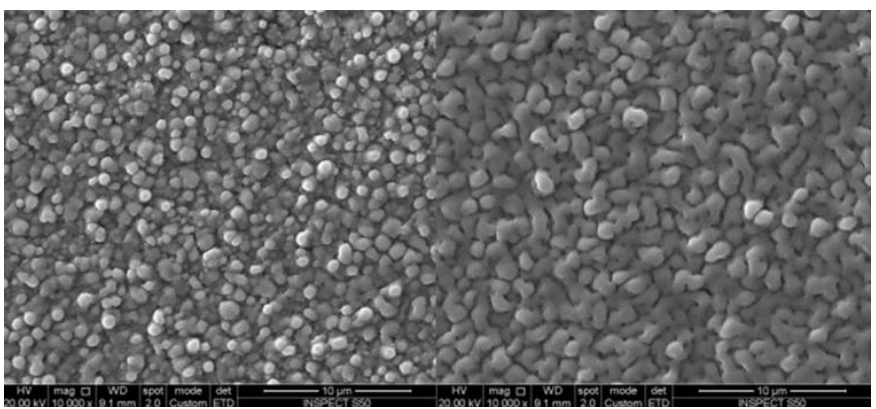

(a)

(e)

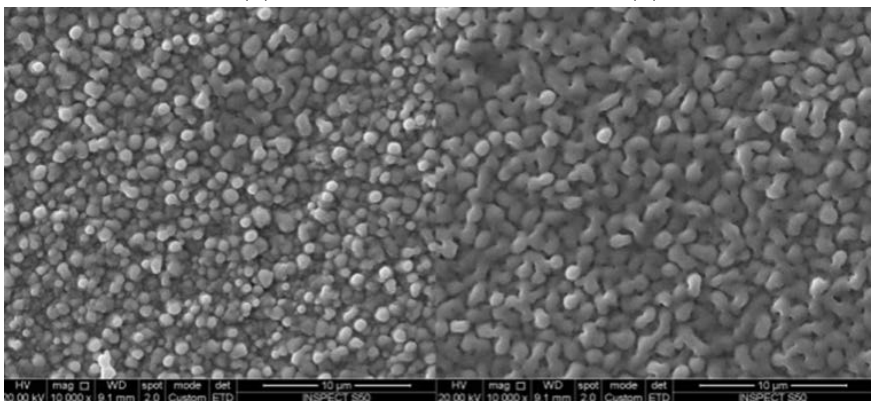

(b)

(f)

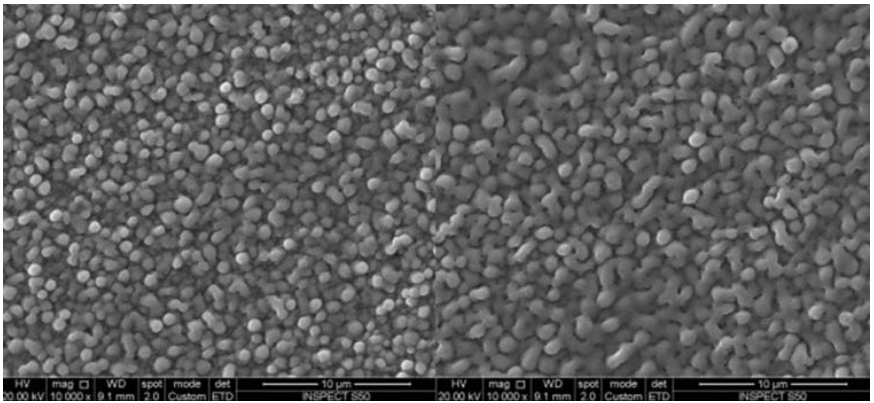

(c)

(g)

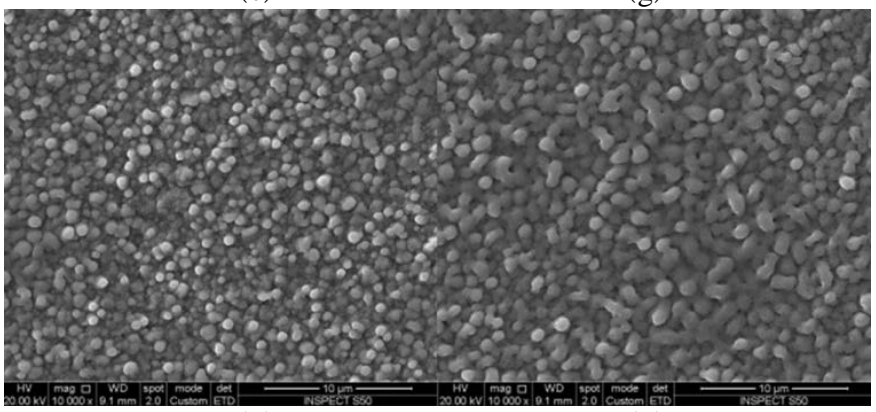

(d)

(h)

Fig.4 SEM images of (a-d) hemispherical textured Ni-Co alloy coating surface induced by different scanning speeds $(2.54 \mathrm{~mm} / \mathrm{s}$, $7.62 \mathrm{~mm} / \mathrm{s}, 15.24 \mathrm{~mm} / \mathrm{s}, 25.4 \mathrm{~mm} / \mathrm{s}$ ) at $0.03 \mathrm{~J} / \mathrm{cm}^{2}$ and (e-h) half-elliptic textured Ni-Co alloy coating surface induced by different scanning speeds $(2.54 \mathrm{~mm} / \mathrm{s}, 7.62 \mathrm{~mm} / \mathrm{s}, 15.24 \mathrm{~mm} / \mathrm{s}$, $25.4 \mathrm{~mm} / \mathrm{s}$ ) at $0.05 \mathrm{~J} / \mathrm{cm}^{2}$. 


\subsection{Nanotribological properties of the textured Ni-Co surface}

Different sizes of hemispherical and half-elliptic nanoprotrusions were fabricated by varying power and scanning velocity. AFM, with a colloidal probe, was selected to investigate the nanotribological properties of textured Ni-Co alloy coating surfaces. A colloidal probe can accurately reflect true contact status and the nanotribological properties of the textured $\mathrm{Ni}-\mathrm{Co}$ alloy coating surface [21].

Fig. 5 shows friction force versus load curves for textured surface made at different laser energy densities $\left(0.03 \mathrm{~J} / \mathrm{cm}^{2}, 0.05 \mathrm{~J} / \mathrm{cm}^{2}\right.$, and $\left.0.18 \mathrm{~J} / \mathrm{cm}^{2}\right)$ at the same scanning velocity of $15.24 \mathrm{~mm} / \mathrm{s}$. The loads in this experiment were set to change from $0 \mathrm{~V}$ to $1 \mathrm{~V}$ and because a voltage signal is proportional to the real friction force, the friction force and load can be calibrated by voltage [22]. To guarantee the accuracy of the friction force data, each data point was an average of five replicates. As shown in Fig. 5, the friction force increases linearly with load whether, or not, the area was processed by laser direct writing. It was also found that the friction force changed with laser energy density used. As the laser energy density increased, the friction force decreased. The area processed at a laser energy density of $0.05 \mathrm{~J} / \mathrm{cm}^{2}$ had the biggest friction force. In other words, the hemispherical textured surface had the least friction force. Hence, friction on the Ni-Co alloy coating surface can be changed by different nanotextures. At $0.05 \mathrm{~J} / \mathrm{cm}^{2}$, the half-elliptic nanotextured surface had the best friction-reducing performance.

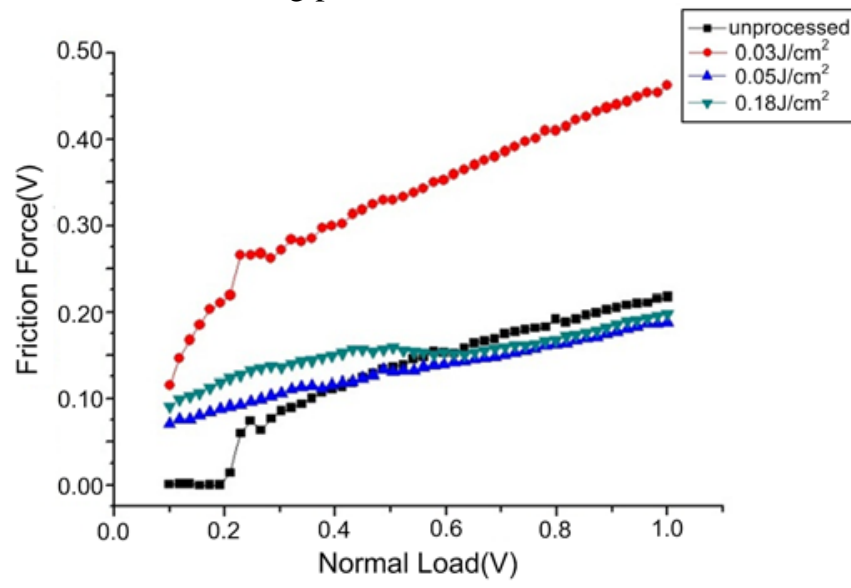

Fig.5 Friction force versus load plots: textured Ni-Co coating surfaces prepared at different laser energy densities.

Generally, two key factors influencing the friction forces at the nanometric scale in the interface contact are real contact area and surface chemistry [13, 23]. With regards the chemical aspects, Krim [24] described the friction force using Eq. (1):

$$
F=f \times W+\alpha_{0} \times F_{a d}
$$

where $F$ represents the friction force, $f$ denotes the coefficient of friction, $W$ denotes the load, $\alpha_{0}$ denotes the coefficient of adhesion, and $F_{a d}$ the adhesion force. When the contact is at the nanoscale, the adhesion forces between friction pairs are an important part of the overall frictional resistance: adhesion forces are also considered as intrinsic thereto [9]. Intrinsic adhesion is mainly caused by capillary, electrostatic, and van der Waals forces, depending upon the nature of the interacting surfaces [25]. In this experiment, the real area of contact became the important factor causing changes in the friction force. According to the interface friction equation deduced by Bowden and Tabor, the friction force is related to the real contact area (Eq. (2)):

$$
F_{f}=\tau A
$$

where $\tau$ is the shear strength and $A$ is the real area of contact. For a pseudo-single asperity contact at the nanoscale, the contact area can be calculated using a contact mechanics models, such as the Hertzian or JKR models. Eq. (3) gives an expression for the contact area according to the JKR model [26]:

$$
A_{r}=\pi\left\{\frac{R}{K}\left(F_{\mathrm{n}}+6 \pi \gamma R\right)+\left[12 \pi \gamma R F_{\mathrm{n}}+(6 \pi \gamma R)^{2}\right]^{1 / 2}\right\}^{2 / 3}
$$

Where, $R$ is the size of the ball, $K$ is the effective elastic modulus, $F_{n}$ is the applied normal load, and $\gamma$ is the interfacial energy of the material.

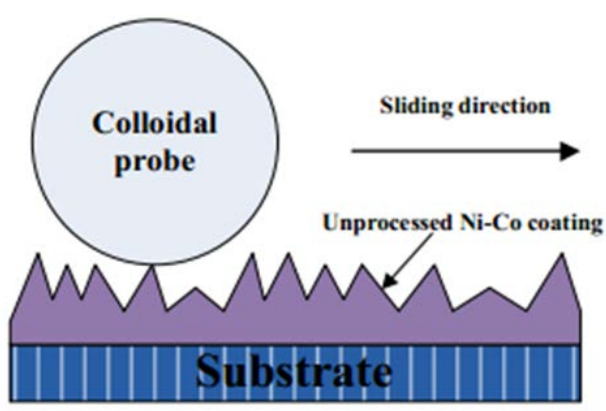

(a)

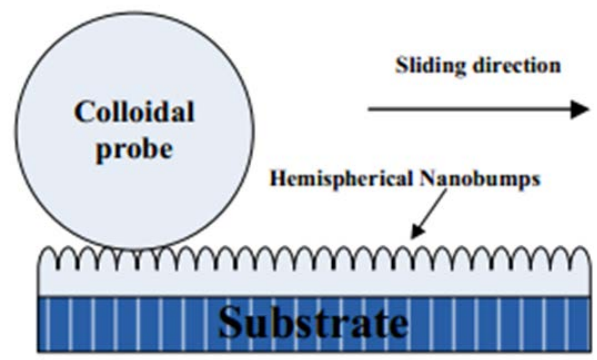

(b)

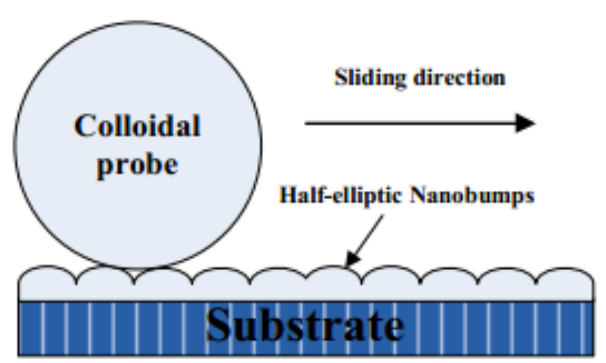

(c)

Fig.6 Schematic diagram of the contact between the colloidal probe and different surface conditions.

To understand better the role of nanoprotrusions in the tribological behaviour of $\mathrm{Ni}-\mathrm{Co}$ alloy coating surfaces, a schematic diagram of the contact between the colloidal probe and different nanoprotrusions is shown in Fig. 6. The colloidal probe is scanned over the coating surface from left to right. In Fig. 6(a), the colloidal probe slides on the 
unprocessed coating surface; because of the rough surface and shape contact asperities, the real contact area is small and unstable, especially at a low load range from $0.1 \mathrm{~V}$ to $0.3 \mathrm{~V}$. As the loads increase, the friction force becomes stable. In Fig. 6(b), the colloidal probe slides on the hemispherical textured coating surface. The hemispherical nanoprotrusions are arranged neatly. The nanoprotrusions are of the same height and the colloidal probe makes contact with many hemispherical nanoprotrusion, therefore the real contact area is bigger than that of the unprocessed region. Fig. 6(c) shows that the colloidal probe slides on the half-elliptical textured coating surface. Compared to the hemispherical nanoprotrusions, the surface of the half-elliptic nanoprotrusion is smoother. The colloidal probe only makes contact with a few half-elliptical nanoprotrusions so the real contact area with the half-elliptical textured coating surface is smaller than that in the unprocessed area. Thus the friction force between materials can be reduced efficiently.

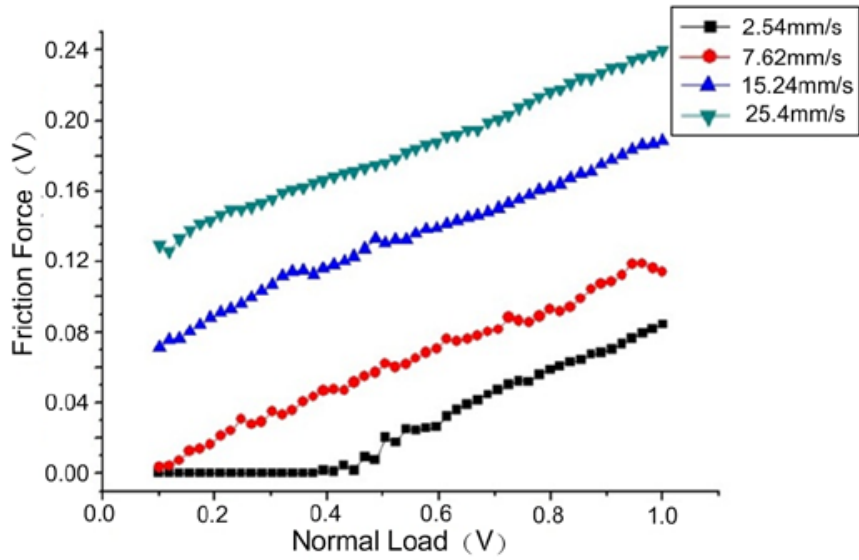

(a)

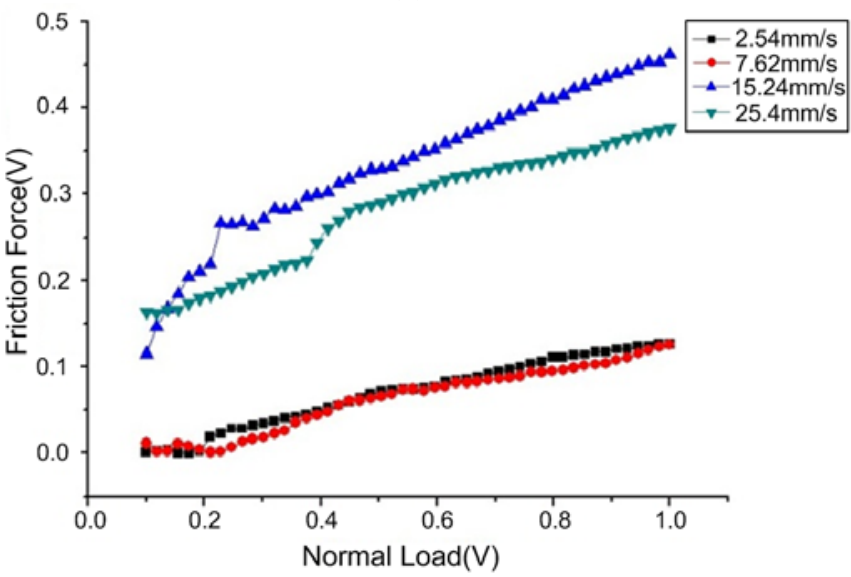

(b)

Fig.7 Friction force versus load curves for the different kinds of textured Ni-Co coating surface with different laser scanning velocities. (a) half-elliptic textured surface at laser energy density of $0.03 \mathrm{~J} / \mathrm{cm}^{2}$; (b) hemispherical textured surface at laser energy density of $0.05 \mathrm{~J} / \mathrm{cm}^{2}$.

In Fig.7, friction force versus load plots for different textured surfaces with different laser scanning velocities ( $2.54 \mathrm{~mm} / \mathrm{s}, 7.62 \mathrm{~mm} / \mathrm{s}, 15.24 \mathrm{~mm} / \mathrm{s}$, and $25.4 \mathrm{~mm} / \mathrm{s}$ ) and are shown. As shown in Fig. 7(a), the friction force increased with increasing scanning velocities on the half-elliptic textured surface at the same load. When the scanning velocity was $2.54 \mathrm{~mm} / \mathrm{s}$, the friction force on the half-elliptic textured coating surface was the smallest. This was mainly caused by the real contact area. The faster laser scanning velocities meant a smaller size of nanoprotrusion was formed. Compared to the radius of the colloidal probe, the smaller size of nanoprotrusion increased the real contact area, so the friction force increased with increasing scanning velocity. Fig. 7(b) shows that the friction force changed with increasing scanning velocity at the same loads on the hemispherical textured coating surface. The variation in friction force was different from that on the half-elliptical textured surface, but the overall trend was the same. The bigger the hemispherical nanoprotrusion, the smaller the real contact area and the smaller the friction force. When the scanning velocity was $2.54 \mathrm{~mm} / \mathrm{s}$, the friction force on the hemispherical textured coating surface was the smallest.

\section{Conclusions}

Controllable nanotextured coating surfaces were fabricated by laser direct writing. An AFM with a colloidal probe was used to investigate the nanotribological properties of these nanotextured surfaces. The following conclusions may be drawn:

(1) Different kinds of controllable nanotextured surface can be fabricated by laser direct writing. Through SEM images of laser processing regions, the laser energy density can control the morphology of Ni-Co alloy coating surfaces, especially at a laser energy density of $0.03 \mathrm{~J} / \mathrm{cm}^{2}$, the coating surface was covered with hemispherical nanoprotrusions and at a laser energy density of $0.05 \mathrm{~J} / \mathrm{cm}^{2}$, the coating surface was covered with half-elliptical nanoprotrusions. The sizes of these nanoprotrusions were related to the laser scanning velocities used: the faster scanning velocities generated smaller nanoprotrusions.

(2) The friction force versus load plots were derived from AFM measurements using a colloidal probe. From these, it was found that the textured surfaces exerted a significant influence on frictional behaviour. Some kinds of textures can increase frictional resistance; others can decrease it. The friction force increased with increasing laser scanning velocity.

\section{Acknowledgement}

The author gratefully acknowledges the Fundamental Research Funds for the Central Universities under Grant (2015QNA35) and A Project Funded by the Priority Academic Program Development of Jiangsu Higher Education Institutions (PAPD) for supporting this work.

\section{References}

[1] S. Grilli, V. Vespini, P. Ferraro: Langmuir. 24, (2008) 13262.

[2] N.S. Tambe, B. Bhushan: Nanotechnology. 15, ( 2004) 1561.

[3] Y. Wang, Y. Guo, R. Cui, Z. Wang, Y. Wu: Science and Engineering of Composite Materials, 21, (2014) 471.

[4] H.W. Liu, B. Bhushan: Ultramicroscopy. 97, (2003) 321.

[5] R. Maboudian, R.T. Howe: J. Vac. Sci. Technol. B. 15, (1997) 1. 
[6] J. Bonse, S Hohm, R. Koter, M Hartelt, D Spaltmann, S. Pentzien, J. Krüger: Applied Surface Science. 374, (2016) 190.

[7] J. Bonse, R. Koter, M. Hartelt, D. Spaltmann, S. Pentzien, S. Höhm, J. Krüger: Applied Surface Science, 336, (2015) 21.

[8] J. Bonse, R. Koter, M. Hartelt, D. Spaltmann, S. Pentzien, S. Höhm, J. Krüger: Applied Physics A, 117, (2014) 103.

[9] D. P. Singh, A. K. Singh, O.N.Srivastava: J. of Nanosci. Nanotechnol. 3, (2003) 545.

[10] H. Yang, H. He, E. Zhao, J. Hao, W. Tang, H. Zhu: Laser Physics Letters, 11, (2014) 105901.

[11] H. Yang, H. He, J. Han, J. Hao, W. Tang, H. Zhu: Laser Physics. 24, (2014) 065901.

[12] Y. Wang, H. Yang, J. HAO, Q. Han, L. FANG, S. GE: LASERS IN ENGINEERING.21, (2011) 241.

[13] W. Zhao, L. Wang, Q. Xue: Colloids and Surfaces A: Physicochem. Eng. Aspects. 366, (2010) 191.

[14] Butt H.J, Cappella B, Kappl M: Surf. Sci. Rep. 59, (2005) 1.

[15] Halperin A, Zhulina E B: Langmuir. 26, (2010) 8933.

[16] Ducker. R, Garcia. A, Zhang. J, Chen .T, Zauscher. S: Soft Matter. 4(9), (2008) 1774.

[17] Edit Kutnyanszky, G. Julius Vancso: European Polymer Journal. 48, (2012) 8.

[18] W. A. Ducker, T. J. Senden, R. M. Pashley: Nature. 353, (1991) 239.

[19] X. Zhang, Y. Lu, E. Liu, G. Yi, J. Jia: Colloids and Surfaces A: Physicochem. Eng. Aspects. 401, (2012) 90.

[20] H. R. Fischer, E. R. M. Gelinck: Applied Surface Science. 258, (2012) 9011.

[21] X. Zhang, X. Wang, W. Kong, G. Yi, J. Jia: Applied Surface Science. 258, (2011) 113.

[22] S.Y. Song, S.L. Ren, J.Q. Wang, S.R. Yang, J.Y. Zhang: Langmuir. 22, (2006) 6010.

[23] Y.C. Jung, B. Bhushan: Nanotechnology. 17, ( 2006) 4970.

[24] Krim J: LUBR ENG. 53, (1997) 8.

[25] B. Bhushan, A.V. Kulkarni: Thin Solid Films. 278, (1996) 49.

[26] K. L. Johnson, K. Kendall, A. D. Roberts: Proc. R. Soc. London A. 324,(1971) 301.

(Received: May 19, 2016, Accepted: November 27, 2016) 